\title{
Vygotsky Theory on Social Interaction and its Influence on the Development of Pre-School Children
}

\author{
Dr. Marta Topçiu \\ Education Sciences, Department of Teaching Methodology \\ Faculty of Education Sciences, University "Aleksandër Xhuvani", Albania \\ martatopciu@yahoo.com \\ Dr. Johana Myftiu \\ Education Sciences, Psychology Department, \\ Faculty of Education Sciences, University "Aleksandër Xhuvani", Albania \\ johanamyftiu@hotmail.com
}

\begin{abstract}
The continuous process of human recognition has been explained by different schools of psychology. Among them, social constructivism emphasizes the importance of social environment, culture and social interaction with others, in this process. This study aims to highlight the role of using effective techniques and strategies that allow the possibility to study with the help and interaction with others in the pre-school age. The knowledge and application of the scaffolding technique within the Zone of Proximal Development helps accelerate the cognitive development of the child, making the learning process more dynamic and the child more active. The idea of dialog is very important and every child should feel as an integral part of social interaction. The efficient use of these techniques shows an optimization of the child's achievement. The process of transforming spontaneous concepts into scientific ones, is facilitated and accelerated. It is important for the help to be offered in an individual way, when and where needed. Also, it is required that the educators and teachers be trained for the successful use of these psychological mechanisms.
\end{abstract}

Keywords: social interaction, scaffolding, the Zone of Proximal Development, pre-school children.

\section{Introduction}

The construction of human recognition is affected by bio-psycho-sociological factors. There have been many debates on their role and the theories that try to explain them have their specific nuances. We can mention here the theory of "operational interaction from Piazhe", "learning through mediation from Vygotsky", the Bruner theory, etc. Among them, the social constructivist theory supports the idea that the social factor affects, facilitates, and accelerates the socio-cognitive development of the individual.

The child's personality is also affected by these factors. Depending on its level of development, the role of the social environment is different and as a result, the modification of the mental structure is different in each child. In this journey, the modification is reached when the child is active in this factor interaction.

Seen from this point of view, the education environments of preschool children should bring and promote those modalities and structures which favor the social interaction role among them and adults (teachers, educators) or their more capable peers. The prevailing philosophy which supports and highlights the role of the social factor in learning is the theory of Vygotsky and his followers. His concept of the Zone of Proximal Development, followed by instruments like "scaffolding" are psychological mechanisms which should be acknowledged and applied in class to help the child efficiently pass this distance. 
According to Vygotsky, although the biological factors constitute the necessary preconditions for the natural elementary processes to appear and develop, the sociocultural factors are also important.

The following questions need to be addressed:

- Does the curricula and philosophy on which it is based, offer the chance to use the socio-cultural constructivism theory in preschool classes?

- Do teachers know the advantages of this learning model?

- $\quad$ Are teachers capable to make the necessary social adjustments in order to optimize the understanding and possession of different concepts and behaviors by children?

From the observations made in several preschool educational institutions in our city Elbasan, it is observed that not all teachers know the main concepts of this model. Even in cases when they have the necessary knowledge about these concepts, they face difficulties in the efficient practical use of the specific instruments which help children accelerate their psycho-social development.

It is necessary to know researches done about this model, the results of the studies, and their application when practicing education. Also important are the suggestions and necessary techniques which teachers and educators need to know in order to use them efficiently.

\section{Theoretic framework, main concepts in the socio-cultural theory and research findings}

The most know representative of the social-cognitive constructivist theory is Vygotsky. The focus of his work is the individual's interaction with society, the impact of social interaction, the language and the learning culture. He aimed to explain the role of dialogue in structuring recognition and viewed the origin of cognitive functions as a product of social interaction. "The human learning means a specific social natyre and a process through which children enter gradually in the intelectual life of people sorrounding them" (Lev. S. Vygotskij, 1934).

Lantolf (2000), confirms that base on the main concepts of the sociocultural theory, the human mind is mediated.

According to Vygotsky (1978, cited Lantolf 2000), the sociocultural environment confronts children with a diverse set of taska and questions. In early stages, the child is completely dependent on other people, especially on parents, who initiate his decisions while instructing him what to do, how to do it and what not to do. Initially these are realized through language, which plays a big role in the way the child adapts to the social enheritance. Vygotsky (1978 cited Wertsch 1985) declares that the child recieves the knowledge initially through the contacts and interactions with people, and then assimilates this knowledge adding the personal values in it. This passage from the social to the personal qualities, is not a simple imitation but a transfer of what has been learned from the interaction to the personal values. Vygotksy admits that this is what happens in schools. Children do not only copy what has been offered by the teachers but also trasform them during the learing process. According to this theory, the interaction between teachers and children has a dynamic nature and learning happens as a result of this interaction.

Ellis (2000) believes that the socialcultural theory of learning starts not through interaction but during interaction. At first, children finish a task with the help of another person, learn it and then are able to do the same task alone. In this way, the social interaction is a support to intermediate learning. According to Ellis, the socialcultural theory supports the idea that sucessful interactions are those during which children are helped to finish new tasks. One of the most important contributions of Vygotsky's constructivist theory is the difference it makes to the current level and the potential developement, or the so called "Zone of Proximal Development" (ZPD).

\subsection{Zone of Proximal Development (ZPD)}

Lantolf (2002), Wertch (1985) and Shayer (2002), admit that Vygotsky introduced the ZPD concept because he did not approve the way the children's intelectual abilities were being evaluated. According to him, the techniques developed for testing the children define only the current level of development, but do not measure their potential capabilities. He strongly 
supports the view that psychology should study "what one is not yet", so with what is expected to come and what is possible to be reached. He introduced the concept of ZPD, which he defines as: "'the distance between a child's actual developemental level as determined by independent problem-solving, and the higher level of potential development as determined through problem-solving under adult guidance or in cooperation with more capable peers (Werstch, 1985, p.60). In other words, this means introducing two different presentations of a child: without or with the help of a partner (Carugati F. \& Selleri P., 2001, p.51).

The transition from a spontaneous concept to a scientific one, which affects the intelectual development of a child, is neither automatic nor spontaneous. This development is reached through the adults' interference and exactly in this moment appears what Vygotsky calls the learning process.

ZPD helps determine the mental functions of the child which have not yet matured, but are on the process of maturing, functions which are in the embryonic phase but will mature tomorrow. The teacher should not be limited to what the child can do today but to what he would be able to do, if help was offered. (Aprile L., 2010. p.339). Through the help of an adult or the more capable peers, in the ZPD appear a series of inner development processes, which later become part of the independent achievement. The instruction and development are two different processes which are joined together through a mutual complex relationship.

According to Shayer (2002), Vygotsky supports the idea that a good instruction should proceed ahead development and should awaken and push for the invigoration of a set of functions that are in the maturity phase and lie in ZPD. This way the instruction can play a big role in development. He goes on suggesting that teachers are responsible for offering the learning context in which the intruction moves ahead of development and leads it. Shayer claims that ZPD application in school practice is not easy. A problem observed in school texts is linked to the fact that what it means to help the children progress from a level to another and which is the teacher's role in facilitating this progres. Teachers and educators should enter where and when needed in ZPD. Several important means have been discussed, like intermediation, which is central to the sociocultural theory and the scaffolding which is mentioned by the cognitive psychologists.

\subsection{Scaffolding}

The term "scaffolding" has been introduced in by Wood et.al. (1976) and means 'to create a scaffold' or to provide an external support through something that helps construct a building. However, this a metaphor that helps understand the used modalities by adults to organize their activities with kids (Carugati \& Selleri, 2001).

The scaffolding describes the process of transition from teacher assistance to independence. It answers the frequently asked question about the ZPD: if a child can function at a high level only with assistance, how can this child eventually be able to function at the same level independently? (Bodrova, E. and D.J. Leong. 2001, p.11).

Donato (1994) states that scaffolding is a concept coming from congnitive psychology. He confirms that during social interaction, a more capable participant, through the use of language and other supportive conditions, may help the child move forward to a higher lever with the knowledge and skills owned (cited Turuk C. M., 2008, p.252). In education, scaffolding is an instructional structure through which the teacher models the strategy or task of learning and then moves this responsibility to the children. According to Tharp and Gallimore (1988), learning, especially in schools can be seen as 'achievement with help'(cited Pollard \&Tann, 1993 p.111).

The use of the supportive scaffold facilitates, helps and accelerates the children's task of learning. "When the teacher and peers use scaffolding in cooperative learning, the learning improves" (Krajcik \& Blumenfeld, 2006; Peery, Truner \& Meyer, 2006; Pressley et al.,2001; Yarrow \& Topping, 2001). However, this raises the question of how capable is the teacher to choose the right type and quantity of help, in order for the child to finalize the task in an independent way, and be as succesful as when the task was done with help. Studies point out that if an answer is not provided for this question, scaffolding will remain a metaphor and not an intructional strategy to be used.

Vygotsky's followers bring a set of means through which we can mention the usage of the inner language by children. Especially children in preschool and elementary school can benefit a lot from it. According to Lurias (1979), the inner language has another important function: it helps the children fix their outside and mental behaviour (Berk\& Winsler, 1995); 
Galperin, 1992). On the other hand, the symbolic or dramatic game, which is present during the preschool age, plays a special role in the Vygotsky theory of learning and development.

A more specific study on the supportive scaffold has been presented by Donovan and Smolkin (2002), who analyze this concept in children's writing. They have researched the role of different levels of the supportive scaffold in children's understanding and in showing their knowledge. Tasks are ranked from those that need a minimal support to those that need intermediary and high level of support.

According to Rogoff (1990 in Donato, 1994), during the application of scaffolding, the expert should be active and attentive. He needs to continously review his help and decide when he needs to modify and move it.

\section{Methodology}

\subsection{Instruments}

To answer challenging questions raised in this study, it has been looked into the philosophy on which the curricula and programs that teaching for preschool classes in the city of Elbasan is based. The instruments used for this study are: systematic participatory observation, surveys of preschool teachers of several public kindergartens, as well as case studies.

\subsection{Participants}

In this study have been included four public kindergartens: kindergarten number two, number four, number eleven, and number twelve in the city of Elbasan. The number of preschool teachers who participated in completing the questionnaire is thirty two.

\subsection{Measurements}

\section{Case 1}

In the math center, the teacher gives to the children the assignment to assemble the geometric shapes by size, color and shape. Rosela and Erion group the shapes well by size and shape. Jurgen groups the square and rectangular shapes together.

The teacher tells Jurgen to put the shapes one over the other and observe how they look. Initially Jurgen notices that the shape laying at the bottom is more extended and bigger than the one on the top. As a next step, the teacher helps Jurgen form the square and recktangular shapes with sticks, according to the model.

Then, the teacher asks Jurgen how many sticks he needs to form each shape. She recommends putting the sticks of each form over each other and compare their length. Jurgen says that the sticks of the first shape are all the same while in the second one, two sticks are equally long and two equally short. When the teacher asks how we distinguish these shapes from each other, Jurgen replies: from the length of the sides.

Later on, Jurgen exercises drawing these shapes with the use of a template or by simply joining the shape dots marked by the teacher. Jurgen is now able to identify these shapes in different items or objects inside the classroom. He gives examples of square and rectangular figures in the classroom. By the end of this activity, Jurgen identifies and classifies the geometric shapes by size, color and shape. Therefore, what he first was able to do only with help, now is able to do on his own. 


\subsection{Case studies}

\section{First case}

The girl with initials e A.T cannot write her own full name, but only the first latter of the name. When the teacher asked her why she did not write her name, the girl answered: - I cannot write my name because it is very long, has a lot of letters and I cannot remember them in correct order.

Then the teacher built a "supportive scaffold" and used it for several days in a row in the center of reading and writing.

Firstly: She introduced the model written in capital letters.

Secondly: She would form her name with magnetic letters as per the written model.

At the beginning, she put there only letters needed to form her name. After the girl was able to identify the letters of her name and could arrange them in proper order, the teacher added new magnetic letters.

Thirdly: She started to copy the separate letters of her name by joining the dots.

Fourthly: She could copy her name following the model, by joining dots.

Fifthly: She passed to the stage where she could copy her name as specified in the given model.

Lastly: The girl writes her name as the teacher spells the letters (te folurit e brendshem) in order. For example: $\mathrm{N}$ - like nuts; $\mathrm{L}$ - like lemon; $\mathrm{E}$ - like elephant, and so on. After an intensive work in class and at home with her mother, the girl could write her name on her own. As a result of the joy of being able to write her name, she wrote it in the board, floor, door, hand, paper, etc.

\section{Second case}

The child with initials A.M in the third group faced difficulties in writing the letter ' $r$ '. To overcome this difficulty, the teacher helped the child by holding her the hand to join the dots placed in the paper by her. Later, A.M copied the model given by the teacher and lastly she exercises by writing on her own some lines with the letter ' $r$ '. During this time, the teacher congratulated the child by drawing a star on her notebook. When writing the new letter ' $r r$ ', A.M tells the teacher:

- Teacher, you will not help me by holding my hand because I can write the new letter even if I do not write it beautifully.

\section{Third case}

Before joining the pre-school class, the child with initials E.T has not attended any of the kindergarten groups. A day after the daily activity with the theme "domestic pets" was organized in the art center, the child was asked to draw a domestic pet (dog, cat, rabbit, etc). Watching the drawings of other kids in the activity centers, the child with initials E.T started to cry. When the teacher asked E.T why s/he was crying, E.T answered: I don't know how to draw a cat. The teacher calmed down the child, saying that she was there to help.

- The teacher showed the child the model she had prepared.

- $\quad$ She showed E.T how to draw the cat.

- $\quad$ She explained the drawing step by step.

Then, through oral communication she interacted with the child as following:

- $\quad$ Draw a circle (for the head).

- Draw within the circle, two other joined small circles (for the eyes) and another small circle in the middle (for the nose).

- $\quad$ Below them, draw three "u" letters (for the lips and tongue) and some short lines on the side (for the moustache).

- Draw two small rectangular on the top of the head (for the ears). The teacher held the child's hand to draw the body, legs and paws. 
- Draw a straight line in the middle of the legs in a banana shape (for the tail).

This is the requested drawing. After he did this drawing two-three times, the child could draw the cat and was very happy about this. Therefore, what E.T. could not initially do alone, now is able to do without any help.

\subsection{Investigation: On which philosophy are based the curricula for preschool education in public kindergartens in Albania?}

To get information about the issue we have studied the preschool curricula offered by the Ministry of Education and Sports of the Republic of Albania. Simultaneously we consulted with the board of directors from the District Education Office of Elbasan. This curriculum is based on a standard philosophy that integrates several models, the traditional one with contemporary models, which are child-centered. The teachers are given the opportunity to use elements from several philosophies, like:"Step by Step", "Reggio Emilia", "Montessori". Teachers are free to use a variety of strategies and techniques for the implementation of learning objectives. Giving priority to individualized learning, they are likely to rely on techniques provided by Vygotsky's sociocultural constructivist model.

\subsection{Responses to the survey conducted among teachers of pre-school classes.}

We built a questionnaire with open and closed questions to get information on the recognition and use of Vygotsky constructivist model and its key concepts in the classroom. Questionnaires were distributed in four kindergartens in the city of Elbasan. Out of 32 teachers, 23 of them or $71.8 \%$ said they had heard about the ZPD concept and scaffolding. When asked to give an understanding of these concepts and define which model they belong to, it was noted that 21 teachers (or approximately $62.5 \%$ ) who were also the youngest in age, provided accurate definition of the concept and the model it belonged to. The rest were chaotic and vague in their answers.

- $\quad$ To the question: "Do you use the class scaffolding in class? Mention some types of their use in the classroom ", it was observed that for the first part of the question, the answers were affirmative by 20 teachers (or about $62.4 \%)$. For the second half, only 18 of them (56.2\%) correctly cited the teachers behaviors associated with this concept.

- $\quad$ To the question: "How do you prepare the task you give to children, in accordance with their current level of their development, or slightly above the level of their current development", 22 teachers ( $68.7 \%$ of them), choose the second answer, while 10 of them think that these should be consistent with the current level of development.

- $\quad$ To the question: "Do you think it is necessary to train for this theory of learning" all the teachers gave an affirmative answer.

\section{Analysis and discussion}

\subsection{Analysis of the survey}

From the questionnaire results, it was noted that not all teachers possess the theoretical knowledge and practical skills to implement the concepts and techniques of instruction that suggests Vygotsky theory. The teachers who have clear concepts associated with the Vygotsky theory (21 of them or $62.5 \%$ ), were teachers who learned about these concepts during their education in the relevant branch of study. The rest, 11 of them had greater professional experience and regardless of the fact that in their responses was noticed the use of intuition, by mentioning the concept of "help", their responses did not converged with the true meaning of ZDP and scaffolding concept.

In the questionnaire answers related to the practical use of scaffolding in the classroom, the fact that only 18 of them $(56.2 \%)$ gave correct examples shows that not all the teachers who know the concept are able to use it properly in teaching situations. Despite their examples that according to them were indications of help given to children, these teachers failed to show that help given to the child within the ZDP, through scaffolding is an individualized and specific assistance for each child and not a general, same for all children. 
It is expected that the question regarding the level of difficulty of preparing tasks for children, the number of teachers who felt prepared tasks should be slightly above the level of the current development of the child, was 22, almost equal to the number of the teachers who correctly knew Vygotsky theory concepts.

\subsection{Analysis of the results obtained from observations}

In situations presented and described above, various scaffolding techniques are used. During the participatory observations we made, teachers tried to create and structure learning situations in which children were assisted to pass the area of close development. They used auxiliary questions, specific instructions, various suggestions, models, suggestions, partial solutions, modeling indicated with loud voice etc.

In the first situation, the teacher provides individualized assistance, depending on the child potential. The teacher carefully observing the children understands that child with initial $\mathrm{J}$. needs assistance to internalize the concepts of square and rectangle shapes and this is done by using various forms of scaffolding, as the use of questions, communications and interaction through the use of language, modeling , relying on prior knowledge to move to another level of recognition, ie cognitive progress. The same thing happened with case studies. In all cases, the teacher tried to use scaffolding within the area of close development for children who need help.

From the numerous observations made for this study, in all classes of the preschool education curriculum, teachers are given many opportunities that along with the use of other teaching strategies, to very successfully use the scaffolding instruction as it really optimizes student learning, accomplishes child-centered teaching and individualized learning. In addition, this type of instruction used in these teaching situation, simultaneously helps children gain initial self-regulatory skills, setting goals to earn a behavior or to avoid another. For teachers be successful and effective in the use of this strategy in the classroom, they must know the current level and achievements of each child. Every child is different and the need for assistance is different, not only to different children, but also to the same child in different areas of knowledge. These are clearly identified in the above three cases.

\section{Conclusions}

- Using scaffolding in preschool classes should be seen as an instrument that helps teachers pass from traditional teaching to new various techniques of pedagogy and modern psychology.

- It is important to better understand the basic concepts of the model, features of the supportive scaffold and the quality of teacher-child interaction which is accomplished through dialogue.

- To understand that ZPD is the theoretical basis of scaffolding.

- To understand that scaffolding has attributes that make it different from other types of instructions.

\section{Suggestions}

- The instruction and curriculum should be built and structured to levels that are beyond the current level of the child.

- The teacher must build learning environments in such a way that give children the opportunity to realize the tasks with help and support from teachers and other more capable kids.

- Teachers should observe and follow the psychosocial development of children, to recognize the current level and their development potential and build learning tasks that are in the ZPD of the children.

- Teachers should be careful that the process of learning with help, not to be mistaken with led instructions. 


\section{References}

[1] Aprile, L. 2010. Manuale di psicologia dell'educazione. Piccini, 317-343.

[2] Bodrova, E. and D.J. Leong. 2001. Tools of the Mind: A Case Study of Implementing the Vygotskian Approach in American Early Childhood and Primary Classrooms. Innodata Monographs 7. Geneva, Switzerland: International Bureau of Education. Retrieve from http://www.ibe.unesco.org/publications/innodata/inno07.pdf date 12.4.2015.

[3] Carugati F.\& Selleri P. 2001. Psicologia dell'educazione. II Mulino, Bologna.

[4] Donato, R. 1994. Collective scaffolding in second language learning. In: Lantolf, J. P., ed. Vygotskian approaches to second language research. London: Ablex Publishing, 33-56.

[5] Donato, R.2000. Sociocultural contributions to understanding the foreign and second language classroom. In: Lantolf, J. P., ed. Sociocultural theory and second language learning. Oxford University Press, 27-50.

[6] Lantolf, J.P. 2000. Introducing sociocultural theory. In: Lantolf, J.P., ed. Sociocultural theory and second language learning. Oxford University Press, 1-26.

[7] Lev. S. Vygotskij, pensiero e linguaggio, (1934), cit.in Lidio Miato, La teoria vigotskiana, http:/l www.iprase.tn.it/old/documentacione/Pdf/Teoria_Vygotskij.pdf date 3.5.2006.

[8] Metacognition and Constructivism. Krajcik and Blumenfeld, 2006; Peery, Truner \& Meyer, 2006; Pressley et al., Yarrow \& Topping, 2001. Retrieve from http://peoplelearn.homestead.com/beduc/chapter_6.pdf. date 13.2.2015.

[9] Pollard A. \&Tann S.,1993. Reflective Teaching in the primary school. Second edition,111

[10] Turuk, C. M. 2008. "The relevance and implications of Vygotsky sociokultural theory in the second language classroom", ARECLS 2008, vol5 244-262.

[11] Wertsch, J. 1985. Vygotsky and the social formation of mind. UK: Harvard University Press. 